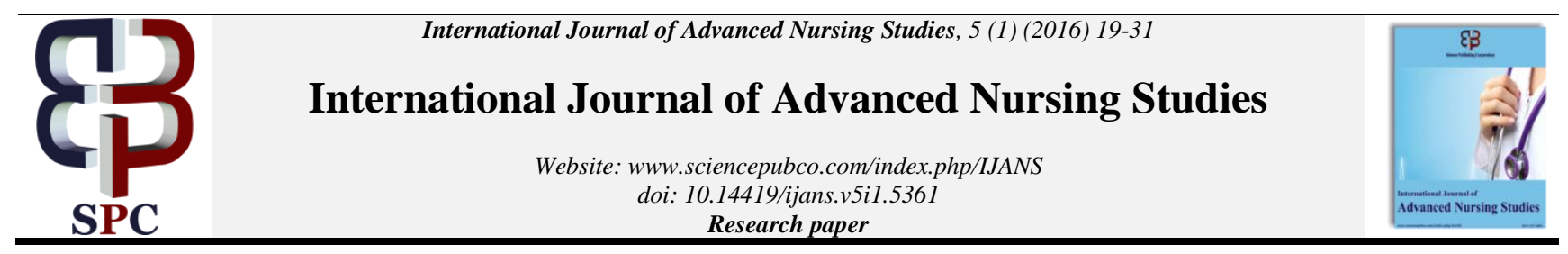

\title{
Description of a model to facilitate male involvement in the reproductive health context by the registered nurses
}

\author{
Amukugo Hans Justus ${ }^{1 *}$, Kareen Jooste ${ }^{2}$, Julia Paula Nangombe ${ }^{3}$ \\ ${ }^{1}$ Lecturers, School of Nursing, Faculty of Health Sciences University of Namibia \\ ${ }^{2}$ Lecturer, School of Nursing, Faculty of Health Sciences University of Western Cape \\ ${ }^{3}$ Quality Assurance and Quality Improvement. Office of Vice President, Veterans Affairs, Republic of Namibia \\ *Corresponding author E-mail: hamukugo@unam.na
}

\begin{abstract}
The aim of this article is to describe a model to facilitate male partner involvement in the RH context. The findings in chapter 3, step1 concept analysis - which comprised the identification, definition and classification of concepts and the construction of an interrelationship between concepts and statements (chapter 4), formed the basis for the development of this model. This model to facilitate male partner involvement in RH is based on the theory generation of Chinn and Kramer (1991). The central concepts are defined by using the rules described by Rossouw (2000/1,) and Copi and Cohen (1996). Lastly, the model evaluation has been done in accordance with the method of Chinn and Kramer (1991).
\end{abstract}

Keywords: Description; Model; Male Involvement; Reproductive Health; Registered Nurses.

\section{Introduction}

Reproductive health is a crucial aspect of the general well-being of individuals because it deals with the health of the individual from conception, through childbirth, and during childhood and adulthood. Health care providers render reproductive health services in all health facilities but, specifically, in antenatal and postnatal clinics both before and after the mothers have given birth. Traditionally, antenatal and postnatal care was regarded as the specific domain of women and children since these services are concerned with pregnancy and childbirth. However, it was realised that men could also play an important role in successful reproductive health. It must be pointed out that couples, partners and individuals all have the right to decide freely on their treatment and that they should have access to all the information and education which is available on reproductive health. This is possible only in an environment in which male partners also participate fully in the of their female partners. This implies that men must play an active role within the reproductive health context (UNFPA, 2003).

Reproductive health $(\mathrm{RH})$ problems are the most challenging problems confronting developing countries. Several studies on indicate that there is a growing understanding within the international public health community on the role of gender as a fundamental influence, together with decision-making power, and access to education on reproductive health, and that this affects the health choices which are available to every individual. This understanding has been instrumental in increasing awareness on the part of the profession on the need to develop creative health care strategies to reach male partners. This need has become increasingly urgent in the face of the growing worldwide spread of STIs, including HIV. In many countries, pilot programmes and initiatives to ensure the involvement of the male partner in the reproductive health services have existed for more than 20 years; however there has been minimal progress. This may be attributed to the fact that policy makers and health care providers appear to assume that men are either not interested or do not fully understand how and why they need to be involved in $\mathrm{RH}$ and also what services are available to them and their partners (Nell, Landry, Wilkinson \& Tzanis, 1998; Walston, 2005 ).The benefit of male partner involvement in reproductive health may expand the rights of men and women; improve family health; ensure better communication with male partners and assist couples in making joint, informed decisions within their households.

In the reproductive health systems in the United States of America (USA), despite the fact that male partners do participate in RH programmes, they are, nevertheless, still dissatisfied about the way in which the programmes are structured with the focus on maternal and childcare and the limited contraception methods available. However, reproductive health is perceived as being successful in that country and male partners do understand and assume their responsibilities (Bureau of Reproductive Health, 2002).

In Eastern Europe and Central Asia RH is also viewed in a positive manner and men participate actively in sexuality and reproductive health programmes. This active participation was evoked by the rapid increase of HIV/AIDS and STIs among young people; inadequate access to quality services for counselling, diagnosis and treatment of STIs, as well as a high maternal death rate (UNFPA, (a) 2003).

A study on the reproductive health system conducted in Sierra Leon revealed that male clients were considered as a constraint in terms of family planning programmes, as female clients only were targeted by healthcare providers (Planned Parental Association of Sierra Leone, 1998). In addition, as a result of both the dominance of men over women and male sexual promiscuity, gender inequity and inequality are critical factors in the spread of reproductive health diseases such HIV/AIDS in Africa (Jackson, 2002).

Samba (1999) and Mbizvo and Basset (1996) indicate that the majority of people in Africa have a limited knowledge in respect of sexuality and reproductive health, while statistics show that 
- $\quad 250000$ mothers and 3 million babies die annually in Africa from complications that are related to sexuality and reproductive health

- one in every four married women have unmet needs as regards contraception

- there were five million new HIV infections in 2001 and, indeed, half of all new HIV infections occurred in people under the age of 25

- worldwide 70000 women die every year from unsafe abortions, while more suffer from infections and other consequences relating to these unsafe abortions (ICPD 2009)

- Domestic violence, rape and sexual abuse are significant causes of disabilities among women (ICPD 2009).

Although the population of sub-Saharan Africa is increasing at such a rapid rate, reproductive health problems and related diseases play a role in the death of millions of mothers and children who die as result of complications related to reproductive health problems (Samba, 1999). The UNFPA, (2003a) suggests that, in order to achieve higher quality reproductive health as well as sexual health, it is vital that male individuals receive information and proper education within the context of reproductive health.

In light of the important role of male partners in reproductive health, there has been an urgent call by governments worldwide to involve them in the health sectors. This call intensified after the International Conference on Population and Development (ICPD) which was held in Cairo, Egypt in 1994 (United Nations, 1995b). The call was echoed by the United Nations $4^{\text {th }}$ World Conference on Women which was held in Beijing, China, in 1995 (United Nations, 1995a). Although reproductive health is a complex subject, both these conferences identified those challenges which need to be placed at the centre of the development of health care services. A request was made to different countries and organisations to readdress gender imbalances and to respect the reproductive rights of men and women as necessary preconditions for improving sexuality and the conferences identified the fact that the role of men had been virtually ignored in the past, especially in respect of sexual and reproductive health. Cultural barriers were among the issues that were recognised as de-motivating factors that prevented males from participating in reproductive health systems (WHO, 1999; UNFPA, 2001).

\section{Description of the model}

In the description of the model, the researcher will use the following headings and subheadings - an overview of the model, the purpose of the model, and the structure of the model. The latter comprises components such as assumptions on which the model is based, and the definition of concepts which consists of theoretical definitions of the central statement and related concepts as well as other related definitions as they appear in the five phases illustrated in the development of the model. The above mentioned components are followed by the process and an evaluation of the model

\subsection{An overview of the model}

A schematic presentation in figure 5.1 illustrates a model to facilitate male partner involvement in RH. Each component of the model will be explained in terms of the way in which it contributes to the model as whole. This schematic presentation illustrates the way in which the registered nurses as agents in a partnership with other significant stakeholders manage the partnership environment in order to facilitate male partner involvement in $\mathrm{RH}$.

The RH environment comprises both an external environment (community) and an internal environment (health facilities). The internal environment consists of health facilities such as clinics, health centres, and hospitals at the different levels - community level, district level regional level and national level - at which the RH services are being offered. Each environment is characterised by interrelated dynamic factors and challenges that both influence and hinder the involvement of male partners in RH. The factors and challenges in respect of each environment may be described as follows:

The external environment (community) in this study comprises the external and internal factors within the community that influence male partner involvement in RH. The challenges (dynamic) in respect of the internal community environment in this study may be expressed in terms of poor interpersonal relationships between the stakeholders, poor communication, negative attitudes, a lack of confidentiality and trust, and personal attributes including shyness and embarrassment on the part of both the male and female partner. The challenges in respect of external community environment that hamper male partner involvement in RH include sociocultural aspects such as polygamous practices, myths about male involvement in RH, gender disparity, migratory labour and abuse of alcohol by male partners.

The internal environment (health facilities) comprises both the external and internal factors that influence male partner involvement in RH. The internal factors include the challenges (dynamics) inherent in the health facility environment and issues such as poor management principles (inadequate policies and legislations); poor infrastructure; staff shortages; poor networking in the health facilities that provide RH services and the lengthy periods of time spent by the partner at the health facilities. The challenges within the external health facility environment in this study may be expressed in terms of, firstly, the inaccessibility of the health facilities arising from long distances and the shortage of transport available to partners wishing to visit the RH facilities. Secondly, the high costs of reproductive treatments and services as well as poor networking in, for example, the wards or departments, also constitute challenges within the external health facility environment.

The agent refers to the researcher, senior registered nurses and other significant stakeholders in either the community or in the health facilities. The primary agent is the researcher who developed a model and strategies for the facilitation of male partner involvement in RH. The co-agent is the senior registered nurses (primary health supervisor) within the health context (environment) in collaboration with influential (significant) people within the community, line ministries and NGOs.

The agents (researcher and registered nurses) in this model possess scientific knowledge and skills (competencies) that will enable them to manage the partnership environment in such a way as facilitate male partner involvement in RH. This knowledge and skills refer to the following:

i) The research conducted that will enable the agent (the researcher) to explore and to describe the needs and challenges that are hampering the process of involving male partners in the RH services. These challenges will form a basis to support the agent during the partnership and management phase to facilitate the involvement of both the male and female partners in RH.

ii) Nursing skills will enable the registered nurse, as the agent, to promote the active participation and involvement of the male partners, female partners, nurses and significant stakeholders in, inter alia, adopting the shared vision, joint decision making, sharing responsibility, collective action and agreement. However, for the stakeholders (male and female partners and the nurses) to achieve the partnership in totality it is essential that communication, networking, motivation and collaboration be strengthened.

iii) Management skills will enable the agent to manage both the external and the internal environment in terms of human, financial, and physical resources, information, time and material through planning, organising, directing and controlling. The underlying dynamic of facilitation of male partner involvement is carried out in four phases, namely, situational analysis, partnership, management and control, and outcome phases. The end product is the involvement of the male partner in $\mathrm{RH}$ is the core and fundamental facet within the $\mathrm{RH}$ context. 


\subsection{The purpose of the model}

The purpose of the model is to provide a theoretical framework for nurses and significant stakeholders within the health facilities to facilitate male partner involvement in the RH context. However, this is possible only if the process takes place through the management of the partnership environment in five phases within the framework of the management process. These phases comprise situational analysis, partnership, management of the human, financial, physical and material resources, information, and time through planning organising, directing and control in order to attain the outcome - "male partner involvement in RH".

\subsubsection{The structure of the model}

The structure of the model comprises the assumption on which the model is based, concept definitions (central statement and related concepts); relationship statements and the nature of the structure (Chinn \& Kramer, 1991). These may be described as follows:

\subsubsection{The assumption}

The Theory for Health Promotion in nursing (Department of Nursing Science, Rand Afrikaans University, 1999) is used as the theoretical framework. This theory views male partners, female partners, nurses and other stakeholders as spiritual beings who function holistically in an integrated, interactive manner with the environment. The primary assumption of this model is based on facilitating male partner involvement through management of the partnership environment. Using the Theory for Health Promotion as a basis, the following assumptions were derived by means of deductive reasoning.

- Male partners, female partners and the nurses are perceived holistically in interaction with both the internal and the external environment.

- The internal (community) and external (health facilities) environments both exert an influence on the involvement of male partners in the reproductive health context.

- The nurse (registered nurse), as agent, requires:

- Research knowledge and skills in order to explore and describe the factors which influence male partner involvement in the RH context and to conduct a situational analysis.

Interpersonal skills such as communication, networking, collaboration and motivation in order to facilitate the partnership between the stakeholders through shared vision, mutual cooperation, the sharing of responsibility, and joint decision-making;

- Knowledge of management principles and strategies in order to plan, organise, direct and control human, financial and material resources, information, and time effectively so as to facilitate male partner involvement in the RH context.

- Male partner involvement within the RH context is both dynamic, and a partnership and interactive process which require input from partners, individuals, families, communities and the government at large.

- Male partner involvement in RH is an ongoing process which requires monitoring, evaluation and the provision of feedback to the stakeholders.

\subsubsection{Theoretical definitions of the central and related con- cepts}

The central statement - "management of the partnership environment" - will be defined first and this will be followed by definitions of the other related concepts as they emerge in phase ones, two, three and four.

\subsection{Definition of the central statement}

The central statement which comprises statement and concepts may be described as follows:

Management of partnership environment: This is a process of planning, organising, leading and controlling human, financial, physical and material resources, information, and time within the context of a sound partnership between the stakeholders. Management of partnership environment comes about as a result of shared vision, networking, mutual cooperation, collaboration, communication, shared responsibility, participation, involvement and joint decision-making in creating a conducive environment in order to facilitate male partner involvement in $\mathrm{RH}$.

Management: Management of the health care delivery institutions implies the managing of human, material, and financial resources, information, and time. During the planning phase goals are set, action plans developed; and implementation and evaluation strategies formulated by the senior registered nurse(s) in collaboration with other stakeholders. The act of organising implies that the registered nurse who is working in the $\mathrm{RH}$ facilities design the structure, assign responsibility, establish the command structure and coordination mechanism to the stakeholders such as male partner, female partner and the nurses. Through leadership the agent manages the dynamic interaction between the stakeholders. Managing includes evaluating the outcome by the setting of standards to measure actual performance, evaluating deviations, rectifying deviations and providing feedback to the stakeholders.

Partnership: A partnership between the stakeholders in order to facilitate male partner involvement in RH implies the adoption of a shared vision, cultural realisation and knowledge, sound interpersonal relationships based on mutual cooperation, collaboration, networking, communication, sharing of resources and responsibilities, joint decision making, trust, respect and confidentiality. A partnership enables the stakeholders to engage in collective action in sharing resources, and addressing challenges and barriers through active participation and involvement in matters concerning $\mathrm{RH}$ issues.

Environment: A conducive internal and external environment to promote male partner involvement in $\mathrm{RH}$ should be created by health care institutions. A conducive environment implies that the male partners feel safe, and not apprehensive. They should also be motivated by encouragement and recognition to become involved. They should receive the necessary emotional support and be treated with respect. The nurses should demonstrate patience with all the stakeholders.

\subsection{Definition of related concepts in respect of the cen-} tral statement

The related concepts will be defined as they appear in the four phases. Some of the definitions of these related concepts are to found in chapter four or else they will defined according to the conceptualisation carried out in chapter 4

a) Phase 1 - situational analysis

In phase 1 the following concepts will be defined:

Situational analysis: Situational analysis refers to a process that involves the examination of a situation, its elements and their relationship. The aim is to provide insights and to maintain a product which is a state of situational awareness (Choo, 2001; Endsley \& Garland, 2000). A situation analysis is conducted within the environment of the RH services with the male partners, female partners and the nurses as stakeholders.

Environment: Environment includes both internal and external factors and conditions that influence male partner involvement in RH. Environments in this study refer to the community and health facilities that provide RH services.

Stakeholders: Stakeholders refers to those individual who influence or are influenced by the decision to collaborate and who are directly affected by the outcomes of the joint venture (Ahlert, Barker, Hoeren \& Klein, 2004). The stakeholders in the RH con- 
text include the male partners, female partners, registered nurses, researcher, and significant stakeholders.

Male partner: The male partner refers to a person in respect of whom a conducive and partnership environment is required in order to involve this person within the RH context.

Female partner: A female partner refers to a person in respect of whom a conducive and partnership environment is required in order to facilitate the involvement of this female partner's male partner within the RH context.

Senior registered nurse: A senior registered nurse is a person who is registered with the Nursing Council and who manages the human, material financial and physical resources (environment), as well as information, and time within the context of a partnership with other stakeholders by utilising management skills and principles in order to facilitate male partner involvement within the $\mathrm{RH}$ context (Republic of Namibia 2004).

Researcher: The researcher in this study is a senior nurse registered with the Nursing Council of Namibia as a nurse in community and psychiatric, nursing, midwifery, nurse education and nurse administration. His knowledge and skills in these fields have enabled him to conduct the research (situational analysis) and to develop a model of the "management of the partnership environment" in order to facilitate male partner involvement in RH (Republic of Namibia 2004).

Significant stakeholders: The significant stakeholders include significant individuals within the community, line ministries and non-governmental organisation (NGO) who possesses the knowledge and skills to facilitate male partner involvement in RH through mutual co-operation, collaboration, communication, sharing of responsibility, joint decision making, trust and confidentiality.

Management process: The management process refers to the process of managing the human, material, financial and physical resources (environment), information and time through planning, organising, leading and controlling within a partnership environment with both primary and significant stakeholders through active participation and involvement in the RH context.

Partnership (relationship):A partnership is a relationship established through a joint agreement with the aim of cooperating in sharing competencies through full engagement in collective actions and joint decision-making, in respect of sharing resources in order to attain a mutual, consensual goal which is in the interests of the community. In other words, a partnership is an interorganisational, synergistic, working alliance formed for a common purpose (EL Ansari, Phillips \& Zwi, 2004). A partnership comprises a partnership agreement and normative framework that governs future interactions between stakeholders, the roles and responsibilities of the stakeholders, the activities and the resources. (Blomqvist, Hurmellina, \& Seppanen, 2005; Kaghan \& Lounsbury, 2006).

In this study the term "partnership" includes a shared vision, cultural realisation and knowledge, a sound interpersonal relationship which is based on mutual cooperation, collaboration, networking, communication, sharing of resources and responsibilities, joint decision making, trust, respect and confidentiality. Such a partnership enables the stakeholders to engage in collective action in sharing resources, addressing challenges and barriers and actively participating in matters concerning RH.

Facilitation: Facilitation may be defined as an enabling process that promotes rendering easy to go forward. Interactive facilitation is dynamic and, in this study, would be characterised by reciprocity between the stakeholders of collaborating health facilities that communicate with each other in order to coordinate collective action so as to facilitate the strategies that promote male partner involvement in RH (Senge, 2001; Kaplan \& Beinhocker 2003, p. 72). In this study, interactive facilitation includes factors such as communication, involvement, participation, collaboration, partnership, motivation and networking

b) Phase 2 - partnership

In phase 2 the following concepts will be defined
Partnership: A partnership is a relationship established through a joint agreement with the aim of cooperating in sharing competencies through full engagement in collective actions and joint decision-making in respect of sharing resources in order to attain a mutual, consensual goal in the interests of the community. In other words, partnership is an inter-organisational, synergistic working alliance formed for a common purpose (EL Ansari, Phillips \& Zwi, 2004; Carnewell \& Carson, 2004). A partnership comprises a partnership agreement and normative framework that governs future interactions between stakeholders, the roles and responsibilities of the stakeholders and derisible the activities and resources. (Sirmon, Rana \& Kostishack, 2000; Blomqvist et al., 2005; Kaghan \& Lounsbury, 2006).

Shared vision: A vision is a dream, aspiration or idea about what the future should be or what the future should look like (Muller, Bezuidenhout \& Jooste, 2006). The term "shared vision" in this study means that both the male and female partner have the same feelings, ideas, and experiences about the future involvement of the male partner involvement in the RH services.

Networking: Networking refers to a process that involves developing and using contacts for information, advice and support selfgenerating and self-organising. Networking also refers to the way in which the human and material are connect in order to attain goals, joint ventures in programmes or services and human. The aim of networking is to gather and disseminate information across work groups; encourage the exchange and sharing of ideas, to offer support, and to foster and to share expertise and services (Barker \& Gaut, 1996).

Mutual cooperation: Cooperation means either doing something together or working towards a common goal aim, while the concept mutual describes either the feeling that two or more people may have for each other or else actions that affect two or more people equally (Oxford Dictionary, 2000). In this study it is expected that both the male partner and female partner should work together to promote male partner involvement in $\mathrm{RH}$.

Collaboration: Collaboration refers to interactive mechanisms that inquire into and reflect as approaches in developing collective thought and coordinated actions (Christies, 2000). Through collaboration different perspectives are examined, new ideas and possibilities are explored and common knowledge derived from the integration and synthesis of those ideas that are relevant to the facilitation of male partner involvement in RH (Senge, 1993; Bohm, 1996).

Communication: Communication refers to the transmission of information/messages from the sender (agent) to the receiver (recipient) in such a way as to enable the effective receipt of the information/messages (Daniels, Spiker \& Papa, 1997). Effective communication promotes both the sharing of information and efficient decision making, both of which may be relevant to the stakeholders during the development of strategies to promote male partners involvement in RH (Clark \& Maas, 1998, p. 218).

Sharing responsibility: A responsibility refers to a duty to take care of something (Oxford Dictionary, 2000). In this study the sharing of responsibilities means that both the male partners and the female partners should share responsibilities in respect of those activities that related to $\mathrm{RH}$ issues.

Joint decision: A decision is a choice or judgement that is made after considering the best course of action (Oxford Dictionary, 2000). In this study the term "joint decision" is used in the context of the male partners and nurses making decisions together in respect of the common goal of facilitating male partner involvement in $\mathrm{RH}$.

Participation: Participation refers to the act of taking part in activities or events (Oxford Dictionary, 2000). In this study participation is used in the context of the male and female partners both taking part in activities or events that are related in $\mathrm{RH}$.

Involvement: Involvement refers to the act of taking part in something (Oxford Dictionary, 2000). In this study involvement is used in the context of both the male and female partners taking part in activities or events that are related in RH. 
Trust: The responsible acceptance of the control dimension in a relationship. This includes trusting (an admission of dependency on the part of the person involved) and trustworthiness (acceptance of an obligation not to exploit control in an interpersonal relationship (Barker \& Gaut, 1996)). In this study trust refer to the facts that the stakeholders such as male partner, female partner and the nurse should trust one another in order to facilitate male partner to involve in the RH.

Respect: Respect refers to a feeling of admiration which is elicited because of either qualities or achievements. The term may also refer to either courteous behaviour (Oxford Dictionary, 2000).

Confidentiality: Confidentiality refers to a situation in which it is expected that information will be kept secret (Muller et al., 2006; Oxford Dictionary, 2000).

Motivation: The term "motivation" is used to describe both the extrinsic condition that stimulates certain behaviour as well the intrinsic responses that make human beings what they are. The intrinsic response is described in terms of needs, wants and drive (Oxford Dictionary, 2000).

c) Phase 3-management

In phase 3 the following concepts will be described - certain of the definitions are derived from chapter 4 after the conceptualisation of the concepts used:

Management: The management of a health care delivery institution implies managing human, material, physical and financial resources, information and time in order to facilitate male partner involvement in the RH context.

Planning: Planning refers to a process in terms of which goals are set, action plans developed, and implementation and evaluation strategies formulated by the senior registered nurse in collaboration with other stakeholders (Gillies, 1994; Muller et al., 2006).

Organising: The act of organising implies that the health care providers working in the RH facilities design the structure, assign responsibilities, and establish the command structure and coordination mechanism to in order to facilitate male partner involvement in RH (Muller et al., 2006).

Directing: Directing refers to the give of instructions (Oxford Dictionary, 2000; Muller et al., 2006). In this study the agent, the registered nurse, uses leadership and management principles as well as strategies of management to facilitate male partner involvement in $\mathrm{RH}$.

Leading: Leading involves showing the way or persuading others to go in the right direction (Oxford Dictionary, 2000; Muller et al., 2006). In this study the agent, the registered nurse, uses leadership and management principle to facilitate male partner involvement in the RH.

Control: Control refers to the power to make decisions about the way in which an area or an organisation is run (Oxford Dictionary, 2000; Muller et al., 2006). In this study control include evaluating the outcome by setting the standard, measuring actual performance, evaluating deviations, rectifying any deviations by stakeholders and providing feedback.

d) Phase 4 - maintaining a conducive environment

The concepts in phase 4 are defined as follow:

Conducive environment: A conducive environment implies that both the male partners and the female partner safe and not apprehensive. They should also be motivated to become involved by means of encouragement and recognition. The male and female partners should receive the necessary emotional support and be treated with respect. The nurses should evince patience with stakeholders (Voght \& Murrell, 1990; Douglas, Martin \& Krapels, 2003; Hellriegel et al., 1999)

Safe: The term "safe" means that to be protected from any form of either danger or harm (Hornby, 2000).Health facilities include many physical and psychological factors that may influence or affect the life partner in his/her decision either to become involved or not to become involved in RH issues (Perry, 1997) .

Interest (interesting): The term "interesting" may be defined as an act of attracting attention as a result of either a special, exciting or unusual quality (Hornby, 2000). The RH environment should be interesting to both the partners in terms of the availability of ade- quate resources, safety, privacy and recognition of their presence at the health facilities that provide $\mathrm{RH}$ services.

Commitment: A commitment refers to a promise either to support something or to do something correctly (Pearson, 1999). In this study the health facilities and the institutions providing $\mathrm{RH}$ services should be committed to providing quality services in order to facilitate male partner involvement in $\mathrm{RH}$.

Motivation: Motivation is a term that is used to describe both the extrinsic conditions that stimulates certain behaviour as well as the intrinsic responses that make human being what they are. The intrinsic response is described in terms of needs, wants and drive (Geen, 1995; Oxford Dictionary, 2000).

e) Phase 5-control and terminus/outcome

Control: The concept of control was defined in phase 3 .

Terminus/outcome: The terminus or the outcome refers to the end product. In this study the end product of the management of the partnership environment is the involvement of the male partner in the RH context.

\subsubsection{Relationship statements}

According to Chinn and Kramer, 1995, p.96 the relationship statement refers to a description, explanation, or prediction of the nature of the interaction between the concepts of a model. The following relationship statements were formulated in respect of the model to facilitate male partner involvement in the RH context in the Oshikoto Region.

- Management of human, material, financial and physical resources, time and information is deployed to facilitate the attainment of the organisational goals, objectives and outcomes by applying fundamental management activities and principles such as planning, organising, leading and control.

- Senior registered nurses effectively manage resources within in the acceptable partnership environment by utilising management skills and principles to facilitate male partner involvement in $\mathrm{RH}$.

- The management skills needed by the senior registered nurses in the facilitating of male partner involvement in the $\mathrm{RH}$ context include planning, organising, leading and control.

- A partnership is a relationship established through a joint agreement to cooperate in sharing competencies through full engagement in collective actions and joint decision making in order to share resources so as to attain a mutual, consensual goal which is in the interests of the community.

- The significant stakeholders are required to participate actively and to be involved in all the activities through mutual co-operation, collaboration, joint decision making, communication and the sharing of responsibility and resources.

- Male partners require a conducive, partnership environment in order to become involved in the RH context.

- A conducive environment to facilitate male partner involvement in the RH context is a continuous, supportive, no threatening, safe, interested and patient environment with does not elicit feelings of apprehension. Such an environment is characterised by adequate resources, promote, encouragement, commitment, recognition, praise and reward (motivation) in order to facilitate the active participation and involvement of stakeholder so as to facilitate male partner involvement in $\mathrm{RH}$.

\subsubsection{Nature of the model}

The structure of the model includes the central element of the model, concepts, statements and relationships between the concepts. The model consists of the context in which the RH services are delivered, the agent (the facilitator of the process), the recipient (male in partnership with female partner), and the dynamic challenge that hinders male partner involvement in reproductive health procedure, process, and purpose. The following colours were used during the development of the model. The rationale behind using these colours may be described as follow: 
- Green - symbolises life as well as prosperity, healing, cooperation and growth (environment).

- Purple - symbolises healing, peace, royalty, patience and happiness (Outcome of facilitation).

- Blue - symbolises healing, understanding, tranquillity, protection, peace, happiness, mediation, sharpness, the power to perceive, spiritual awareness and patience (partnership).

- Dark blue - symbolises changeability (situational analysis).
- Orange - symbolizes encouragement, strength, ability to concentrate, attraction, adaptability and stimulation (Management).

- Pink - symbolises overcoming of evil, love, friendship, compassion, and relaxation(relationship between male and female partner)

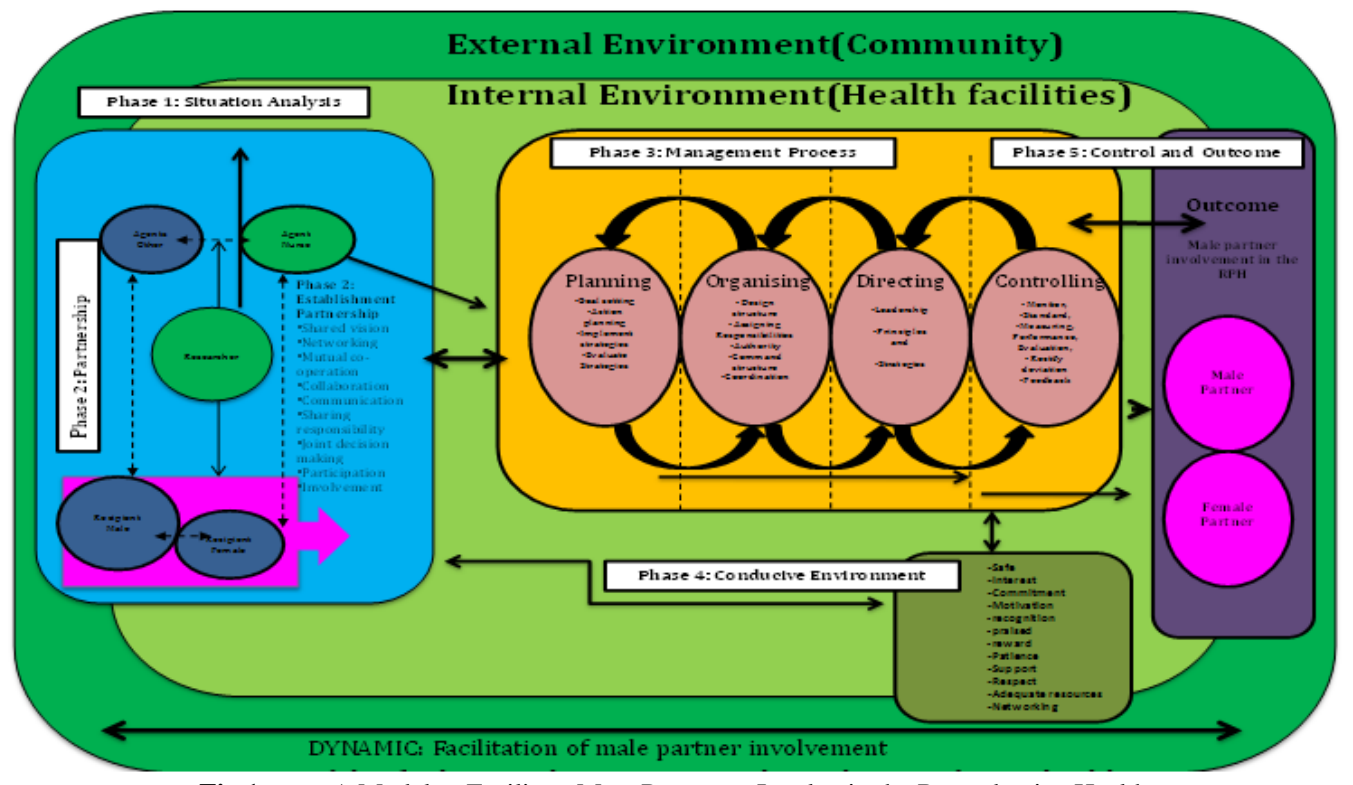

Fig.1: A Model to Facilitate Mate Partner to Involve in the Reproductive Health

The model consists of two rectangles in green (light and dark), which depict the context as the dynamic environment that occurs within the legal and professional boundaries that exert an influence on male involvement in RH. The dark green depicts the external environment while the light green depicts the internal environment.

The community environment (external) signify that, when the male partner, female partner and the nurses enter the health facilities, it is, in the main, the external community environment that influences their perceptions about RH. These influences may be in terms of either accepting or rejecting the services; roles and responsibilities in the RH context.

Within the blue block there are three blue circles which depict the recipient (male partner and female partner) and agent other. Two green circle depict the agent (researcher, and nurses ). The circle which represents the male partner is larger than the other circles as this symbolises negative attitudes, dominant behaviour over female partner, poor communication, aggression and lack of any responsibility towards the female partner. The female partner is depicted by a smaller circle in order to symbolise oppression and voicelessness of women in terms of RH decision making.

The dotted, interlinked line between the male partner, female partner, nurses, researcher and significant stakeholders signify poor interpersonal relationships such as negative attitudes, and poor communication.

The two green circles inside the blue rectangle of the partnership phase represent the agents - the researcher and the senior registered nurse. The green colour symbolises growth of the agent in terms of knowledge and skills in the fields of nursing, management and research in order to manage the partnership environment and carry out a situational analysis.

The blue rectangle depicting for partnership contains a light pink rectangle which embraces the two circles depict the recipients male and female partners with an arrow to indicate the both the partnership and the bond which required in the RH context. Pink was used to symbolise the future relationship between the male and female partners, which would be characterised by love, friendship, compassion and relaxation. This relationship would come about once they had utilised the RH services together.
The underlying dynamic, namely, facilitation, is indicated as a solid line at the bottom of the model, to symbolise the fact that this dynamic is underlying in both the partnership and management phases.

The management process is depicted by an orange rectangle which contains four lines and four circles. The purpose was to represent the management process of planning, organising, leading and control of human, material, financial and physical resources (environment) and time within a partnership and in collaboration with the other stakeholders, either in the health facilities environment or in the community environment. The phases such as situational analysis; establishment of partnership; management process; maintain a conducive environment and termination and evaluation outlined as follows are integrated in the management process (detailed description of these phases in 5.2.4.):

Phase 1 - situational analysis. In this phase the agent utilised research skills to identify the needs and challenges that affect or influence the stakeholders (male partners, female partners, nurses, and significant stakeholders) within the community and health facilities environments. The challenges identified in this phase form the basis on which the agent will deploy the management process in order to manage the partnership environment.

Phase 2 - establishment of partnership: In this phase the agent utilised interactive facilitation processes such as communication, involvement, participation, collaboration and networking. The facilitation of a partnership between the stakeholders so as to promote male partner involvement in $\mathrm{RH}$ implies the adoption of a shared vision, cultural realisation and knowledge, and sound interpersonal relationships which based on mutual cooperation, collaboration, networking, communication, the sharing of resources and responsibilities, joint decision making, trust, respect and confidentiality. Through the partnership the stakeholders engage in collective action in sharing resources, addressing challenges and barriers and participating actively in matters concerning $\mathrm{RH}$.

Phase 3:- management process. In this phase the actual process of facilitation is fully implemented by the agent using management steps such as planning, organising directing/leading and control, as well as leadership policies and guidelines in order to manage the dynamic interaction between the male partners, female partners 
and the nurses during the facilitation process. The facilitation process is implemented on four levels which are indicated with four oval circles joined by a continuous line to symbolise the continuity and ongoing aspect of the facilitation process. The four levels on which the facilitation process takes place may be described as follow:

- Planning in terms of which goals are set, action plans developed; and implementation and evaluation strategies formulated by the senior registered nurse in collaboration with other stakeholders.

- The act of organising implies that either the registered nurse or the nurses working in RH facilities design the structure, assign responsibility to subordinates, and establish the command structure and coordination mechanism in order to facilitate male partner involvement in $\mathrm{RH}$.

- Through the implementation of leadership and management principles and strategies such as time management, conflict management and the management of change the registered nurse manages the dynamic interaction between the stakeholders.

- By setting the standards by which to measure actual performance, evaluating deviations, rectifying any deviations and providing feedback to the partners a registered nurse will be able to determine the degree of male partner involvement in $\mathrm{RH}$.

Phase 4 -maintaining a conducive environment. In this phase the registered nurse perpetuates a conducive environment by ensuring that the environment is safe and interesting and that it is characterised by commitment, motivation, patience, support, respect, adequate resources and networking.

Phase 5 - termination and evaluation. In this phase the agent utilises controlling strategies which include setting standards, measuring the actual performances, evaluating deviations and rectifying any deviations. The provision of sufficient feedback to the partners by the registered nurses is one of the most important measures used to eliminate deviations and to improve active participation of male partner in the RH. . Such feedback assists the agent to formulate specific goals, set measurable targets which must be met at specified times and describe the way in which to attain these targets. As indicated by Levenstein (1984), involving all the partners in the feedback process produces the best results.

\subsubsection{Process description of the model}

The process of the model to facilitate male partner involvement in $\mathrm{RH}$ takes place in four interdependent phases within the RH context. These four phases are as follows:

\subsubsection{Phase 1: exploratory and situational analyses}

This phase involves conducting both an exploratory and a situational analysis in order to explore and describe those factors that are impeding male partner involvement in RH. The aim of the situational analysis is, firstly, to determine the feasibility of the facilitation process aimed at promoting male partner involvement in RH. Secondly, the aim of the situational analysis is to assist the registered nurses to establish a partnership and to manage the human, financial and material resources, and time so as to facilitate male partner involvement in reproductive health.

The situational analysis will be conducted by the registered nurse in collaboration with the other stakeholders within the health facilities as well as with significant stakeholders from either the community, the line ministries or NGOs.

The situational analysis may be conducted in those health facilities that provide RH service at community, district, regional or national level. The health facilities may include clinics, health centers, and hospitals at district, regional and national level. The factors to be analysed include infrastructure, availability of human and material resources, policies and regulations.

The stakeholders to be analysed include the male partners, female partners, the nurses and significant stakeholders in the community.
The situational analysis can be conducted in two sections - community environment and health facilities environment. The findings may be presented as was illustrated in chapter three.

The identification and selection of the key stakeholders will be followed by the joint appointment of the task team to conduct the situational analysis. The function of the task team is to identify the scope of the information required for the situational analysis. The ambit of the analysis includes examining the operational requirements of both health facilities that provide $\mathrm{RH}$ service analysing the information (data) collected by the researcher in the Oshikoto Region, and scrutinising legislation/policy on both RH and gender issues, Nursing Acts, and Nursing regulations (scope of practice of nurse since the nurse will be a major facilitator in facilitation of male partner to involve in the $\mathrm{RH}$

In terms of the external environment the following factors may be analysed - perceptions; interpersonal relationships (attitudes, communication, respect, secrecy, confidentiality, trust, responsibility, and support mechanism) personal attributes (fear, shyness and embarrassment) and socio-cultural barriers (polygamous practices, myths about male involvement in RH, gender disparity and alcohol abuse (misuse) by male partners, migratory labour practices, and household duties).

In terms of the internal environment the following factors may be analysed - accessibility of RH facilities ( distance, availability of transport, costs involved in the RH services and treatments, time spent at the health facilities) policy and legislation, buildings and infrastructure providing RH services, availability of human and material resources to deliver RH services and mechanisms, networking/partnerships between stakeholders and within RH facilities, and, lastly the mechanism of information sharing to empower the stakeholders with the necessary competencies (knowledge, skills and attitudes).

Based on the information uncovered by the researcher in collaboration and in partnership with the other stakeholders the following emerged: the necessity of conducting a resources inventory, and of auditing the capacities, strengths and weaknesses of the human resources, as well the knowledge and skills available to implement facilitation strategies in respect of male partner involvement in $\mathrm{RH}$.

A framework of the findings should provide a structure for presenting the information in a logical way. This framework should identify the outcome of the stakeholders; resources and characteristics and the nature of the health facilities that provide $\mathrm{RH}$. The findings of the situation analysis should include recommendations on the way in which the agent will manage the partnership environment so as to facilitate male partner involvement in $\mathrm{RH}$. This aspect will be discussed in detail in phase 2 (partnership) and phase 3 (management process).

\subsubsection{Phase 2: establishment of the partnership}

After the situational analysis has been conducted the partnership between the stakeholders needs to be established before the management process commences. The agent has a primary responsibility to facilitate this process of this interaction (interpersonal relationships) between the stakeholders. The stakeholders in phase 2 include the nurses, and the male and female partners, as well as other significant stakeholders who are involved in the RH services in collaboration with the nurses. These other significant stakeholders may either be from the line ministries, NGOs and the community. The aim of establishing a relationship between the male partner, female partner and the nurse in this phase is to create and strengthen the interpersonal relationship between the stakeholders by increasing self-awareness, openness, trust, communication, and receptiveness and to motivate male partner to understand the significance of $\mathrm{RH}$.

In phase 2 the agent utilised the interactive facilitation process to establish the partnerships.

According to Charlton (2000), there are two essential purposes for a vision. Firstly, a vision creates an attractive future and motivates people both to find their own roles in a specific programme and to 
work purposefully towards defined goals. Secondly, a vision serves to focus attention on the direction in which the programme is going. According to Barker (1990) a vision provides a framework for both decision making and for conflict. If the vision is explicitly communicated to the individuals then they will tend to change their negative attitudes and behaviour, and to become committed to and optimistic about the programme. Thus, a shared vision among the partners may facilitate male partner involvement in RH. However, the registered nurse as agent is able to foster the partners' commitment to the shared vision only by effectively communicating this shared vision to the partners. The shared vision should always be stressed enthusiastically on a day to day basis whenever the agent encounters the partners. The vision statement should be discussed with the partners, and not simply announced to them. The values inherent in the statement should be clarified. The partners should be encouraged to voice their own opinions about the vision statement as, by doing this, the partners may contribute to the shared vision. Communicating the shared vision serves as intellectual stimulation to the partners. It makes them aware of the problems and, by stimulating thought and imagination and by stressing certain values and beliefs, it enables them to find solutions to the problems that they have in respect of involvement in RH.

The aim of networking is to gather and to provide the information across work groups - encourage the exchange and sharing of ideas, offer support, and foster and share expertise and services. Poor networking between the $\mathrm{RH}$ facilities has resulted in the $\mathrm{RH}$ environment becoming both a complex and a challenging environment. The registered nurse, as agent, possesses the management skills to create an environment that will provide the partners with the opportunity of making use of the resources available. During this stage of networking it is essential that the registered nurse create and develop an environment in which the stakeholders share information and advice and support the partners should they need help (Barker \& Gaut, 1996).

Networking require the active participation of the stakeholders within the community (youth leaders, political leaders, traditional leaders and church leaders) and within the health facilities environment (medical doctors, social workers, psychologists) all of whom identified for the purpose of networking. Secondly, intersectoral collaboration between government ministries, NGOs and other organisation should be identified and encouraged during the networking process.

Mutual cooperation may be defined as the state of doing something together or of working towards a shared aim (Oxford Dictionary, 2000). This type of cooperation is essential between the agent (registered nurse) and the recipient (male partner and female partner), both of whom have the common goal of facilitating male partner involvement in RH. This cooperation is possible only if agents and recipients understand their respective roles in the $\mathrm{RH}$ environment.

Collaboration is an interactive mechanism that encompasses inquiry and reflection as approaches in respect of the development of collective thought and in coordinated actions. Through collaboration different perspective are examined, new ideas and possibilities explored and common knowledge derived from the integration and synthesis of those ideas that are relevant to the facilitation of male partner involvement in RH (Senge 1993; Bohm, 1996).

Communication may be regarded as a process involving the transmission of information/messages from the sender (agent) to the receiver (recipient) in such a way as to be received in an acceptable manner (Daniels et al., 1997, p. 92). Effective communication promotes the sharing of information and the enhancing of decision making which may be relevant to the stakeholders during the development of strategies to promote male partner involvement in RH (Clark \& Maas, 1998, p. 218). It is essential that the registered nurse possess positive attitudes in order to facilitate this process. These attitudes include congruence (the ability on the part of the nurse to be aware of the way in which the male and female partners interacts with the nurses as well the ability to communicate this awareness to the participants), acceptance (the ability to avoid making judgements, either covert or overt) and empathy (not sympathy but capacity of the agent to perceive the nature of the participants' frames of reference accurately).

Sharing responsibility - a responsibility refers to the duty to take care of something (Oxford Dictionaries 2000). In this study the sharing of responsibilities means that the male partners and the female partners share responsibilities in terms of those activities that are related to $\mathrm{RH}$. Both the male and the female partners are jointly responsible to participate in the $\mathrm{RH}$ services for the benefit of both their health as well as that of any siblings. The registered nurse also engages the male and female partners in discussion in order to encourage each partner to share his/her experiences with the other partner. The partners may discuss their stories and experiences in respect of their involvement in $\mathrm{RH}$. Through this interchange of information and experiences they will come to understand their responsibilities and their expected roles in RH. In addition to the above strategies for fostering a greater understanding of their responsibilities in respect of their involvement in $\mathrm{RH}$, the registered nurse, as agent, must strengthen this understanding by empowering both the male and female partners with knowledge and skills about $\mathrm{RH}$ and their roles in respect of promoting the active participation of males in $\mathrm{RH}$.

Joint decision-making within the RH context must be rational and informed so as to enable the partner to play a crucial part in this context. Beyer (1988) defines decision-making as a process of selecting from among a number of alternatives in order to achieve a specific goal. A decision refers to a choice or judgement that is made after consideration about the best possible option (Oxford Dictionary, 2000). Joint decision-making in the context of this study refers to the fact that male partners, female partner and nurses should make decisions together. This process of decision making should be based on justifiable evidence to support the decision made through logical reasoning (Botes, 2000). The registered nurse is responsible for creating an environment that will provide the partners with the opportunity to share in decision-making.

Trust and respect are the foundation of male partner involvement in RH. Trust and respect for the self and for the dignity of others' values, ideas, thoughts and feelings enhance human interaction and social transformation (Pamela \& Loriz, 1998). A lack of trust and respect among the stakeholders (male and female partners and nurse) emerged as a major determining factor influencing the decision of the male partner not to become involved in RH. It is essential that the agent utilise leadership skills in order to establish a trusting and respectful relationship. Trust must be earned and carefully nurtured over time if the male partner is to build such a interpersonal relationship. However, this type of relationship requires patience, consistency, dependability and unending attention over a relatively long period of time.

In this study, trust refers to the fact that the stakeholders, such as the male partner, female partner and the nurse, should trust one another in order to facilitate male partner involvement in RH. It is not merely a case of the nurse being trusted by the partner, as the nurse, as agent, must also trust the partner. The greater the trust that the agent places in the partner and the greater the belief that the partner will change, the greater the possibility that male partner will participate actively in the RH services (Booyens, 1998). If the agent is trusted he/she will find it easier to facilitate male partner involvement in RH. It is to be expected that the registered nurse will possess knowledge and skills in the field of RH, and to be willing to admit mistakes and weakness, to be able to trust his/her subordinates, to spend time listening to the partners, to interpret their body language, to be sympathetic and to respond to problems on the part of subordinates, to be honest, to be open about the programme, and to treat the partners with respect, courtesy, care and concern.

Confidentiality may be defined as a situation in which the registered nurse is expected to keep secret any information with which he/she is entrusted by the partners (Oxford Dictionary, 2000; Muller et al., 2006). This information may include information provided to the registered nurse during the visit of partners to the reproductive health facilities. This information may relate either to an 
interpersonal problem or to the reproductive disease itself. Ehlene and Springer (1998 in Jooste, 2003) describe confidentiality as a situation of support in respect of the protected relationship between caregivers and patients and the guarding of the use of private information. It is vital in context of the $\mathrm{RH}$ services that the nurse maintain the highest standards of professionalism by keeping confidential any information given to him/her by the client in respect of any diseases or problems on the part of the client.

Motivation refers to the concept which is used to describe both the extrinsic condition that stimulates certain behaviour and the intrinsic responses that make human being the way they are. The registered nurse, as agent, in his/her role of facilitating male partner involvement needs to motivate the male partner by ensuring that:

- The need for the male partner to be involved in RH should be clearly indicated - the needs include any deficiencies and actions taken to remedy these deficiencies. These latter actions could include achievement motive, power motive, affiliation motive, security motive (drive or reason) and status motive.

- Incentive motive refers to the alleviating of a need and the subsequent reduction of a drive.

- Manipulation motives: Male partner should also have manipulative motives in order to manoeuvre the culture, beliefs and norms that are hindering the slow pace of male involvement in RH. However, it must be borne in mind that, despite the fact that it is not easy to change culture.

- $\quad$ Activity motive: The male partners must be made to realise that active involvement in the RH services, for example, attending RH facilities with their partners, will be of benefit to both partners as this attendance could assist the partners to understand their problems and needs in totality and also lead to a greater understanding of their families and the community at large. Attending the RH facilities could also enhance the partners' knowledge and skills in respect of $\mathrm{RH}$ issues, and this would, in turn, enable them to solve and to manage the problems affecting their health and that of their families.

- Achievement motive: The male partners should believe that their involvement will make a difference, for example, those male partners who attend the RH facilities should feel that this attendance will be beneficial for their own health and that of their families, that they will gain knowledge and skills and, thus, attain the goal, that they will be enabled to solve the complex problems that are affecting their health and that of their families, they will be able to complete a challenging assignment successfully, and developing a new way of doing something for example to involve in the $\mathrm{RH}$ where it is needed.

- Power motives: The male partners should believe that their involvement in $\mathrm{RH}$ will be influence other people to change their attitudes and behaviour, for example, transform the negative attitudes of other males towards RH issues. Their involvement in RH should also enable them take control of their own activities in respect of $\mathrm{RH}$, to develop the ability to exercise authority especially as regards those activities that affect their own health, although power motives should be done in a shared manner.

- Affiliation motive: The male partners should believe that their involvement in RH will be admired by the majority of community members, and that they will be accepted by the community and by the family. The community should gain the impression that these men are friendly and cooperative. Their involvement RH should enable the male partners to maintain harmonious relationships and to avoid conflict within the family and the community. Finally, the male partners will be given the opportunity to participate in pleasant social activities such as home-based care and AIDS-awareness initiatives.

- Security motive: The male partners should be able to believe that their involvement in RH will be kept confidential and that their needs will be cared for in an holistic manner.
They must feel protected by the caring nurses to whom they are able to divulge their problems. It is essential that they are able to afford the RH programme and services that could protect them against the illnesses and disabilities that may occur as result of reproductive diseases and complications.

- Status motive: The male partners who are actively involved in $\mathrm{RH}$ need to receive recognition and acknowledgement, for example, a token of appreciation for their involvement in $\mathrm{RH}$ should be awarded to these male partners in the form of the opportunity to be treated first or else an introduction during the health education programme which the nurses conduct at the commencement of their duties.

\subsubsection{Phase 3: management processes}

After the situational analysis in phase 1 and the establishment of the relationship between the stakeholders in phase 2 the management phase commences. During this phase the agent endeavours to address different perceptions such as negative attitudes, poor interpersonal relationships, inferior communication, personal attributes of the male and female partners, and the nurses and, sociocultural barriers that might lead to conflict (conflict management), and lack of optimum functioning of the health care delivery system in terms of inaccessibility of RH facilities, poor or inadequate management principles and structure (poor or inadequate legislation and policies) inadequate buildings and infrastructure, inadequate human and material resources, poor networking and, lastly, lack of knowledge and skills on the part of the stakeholder. In order to address these problems the agent employs the management principles of planning, organising, leading and control as follows:

\section{- Planning:}

After the situational analysis of both the external and the internal environment followed by the establishment of the partnership between the agent and recipients, the nurse, as agent, has to plan the facilitation process of involving the male partners in the $\mathrm{RH}$ services. Accordingly, the nurse puts into practice the planning steps of goal setting, developing an action plan and an implementation strategy as well as evaluation strategies in order to assess the attainment of the goal and the outcomes. During this stage the registered nurse should consider whether this action plan is achievable, quantifiable, and time bound. The nurse must also take into account the financial implications and the human resources available.

During goal setting, the vision, mission and value statement for male involvement in RH should be clearly formulated. The aim of the vision, mission, and value statement provide the framework for the resolution of any conflicts which might arise between the stakeholders as interpersonal relationships (negative attitudes and poor communication) play a vital role in RH.

The aim of the vision is to give direction to the stakeholders (male partner, female partner and nurses about future developments, for example, involvement of male partner in RH. Charlton (2000) indicates that, once the stakeholders have understood the vision, they tend to become motivated and to gain clarity in respect of their roles in the programme. This also allows the stakeholders to choose those activities that would enable them to attain the envisioned goal and to avoid wasting time on actions which are not relevant. Vision provides a framework of reference for decision making because the decision makers know the direction in which the programme is going.

In developing the action plans it is essential that the registered nurse identify the key performance areas (KPAs) based on the need identified in the situational analysis. Firstly, the objectives for each identified KPA must be set. Secondly, the activities or action required in respect of each KPA and the attainment of each objective must be drawn up in partnership with the stakeholders. Apart from dealing with the KPAs the registered nurse must assign duties, tasks and responsibilities to the partners - this includes the due dates for the attainment of each objective. Each action plan should be executed in accordance with these due dates. 
Development of implementation strategies: In this step the registered nurse plans the task (KAP) indicated in the action plan in terms of whom, how, when and with what. The registered nurse should come up with polices and guidelines in respect of the execution of each task. These guidelines and policies include:

- Situational analysis policies and guidelines to facilitate male partner involvement in the RH male facilities

- Partnership policies and guidelines to facilitate male partner involvement in the RH male facilities

- Management process policies and guidelines to facilitate male partner involvement in the RH facilities

- Control and outcome policies and guidelines to facilitate male partner involvement in the RH male facilities.

The implementation strategies, such as policies and guidelines to facilitate male partner involvement in $\mathrm{RH}$, need to be formulated in collaboration with the researcher who played a major role in developing both the model and the strategies for this model.

\section{- Organising:}

Organising, as the second step in the management process, needs to be implemented after the goal and the actions plans have been determined, the key performances areas identified, and the policies and guidelines formulated. During this step key performance areas are structured, and human, financial, and physical resources, as well as time and information, are allocated and deployed in a logical and formalised way in order to facilitate optimal utilisation and the attainment of goals and the outcome, namely, male partner involvement in $\mathrm{RH}$.

Designing the structure - this refers to the logical grouping of the key performances areas (KPA), and the detailing of the way in which the activities will be performed and by whom.

Assigning responsibility and authority - once the structure has been designed, the assigning of responsibilities and the authority for each activity will follow. This includes the creation of the organisational relationship between the nurse and the male and female partners, for example, from whom and where to obtain information (directive/instruction), to whom they report and to whom and for what they are responsible.

Establishing the command structure - after the assigning of the responsibilities and the authority to the stakeholders, then the establishing of a command structure will follow. This step includes the establishment of a reporting line in case problems or needs are either identified or arise between the male partners, female partners and the nurses. This establishment of a reporting line entails determining who will report to whom (chain of command ), from whom the partner should receive the order (unit of command), and the assigning of the responsibility to perform activities based on the KPAs identified(requisite authority). This step also includes establishing the authority which the partner may need in order to obtain and to utilise the available resources necessary for the accomplishment a given task. The registered nurse who delegates the responsibility for the performance of a task to a particular partner should bear in mind that this delegation does not mean that the nurse is absolved from the final responsibility for the successful completion of the task (continuing responsibility).

Coordination mechanism - refers to the process of linking and integrating the those activities which were indicated in the designing of the structure, the assigning of responsibility and authority and the establishing of the command structure into a single integrated unit in order to facilitate the realisation (goal and outcome) of male involvement in $\mathrm{RH}$.

\section{- Directing and leading.}

After the planning and organising activities in respect of the management of the partnership environment in order to facilitate male partner involvement in $\mathrm{RH}$, the third management step of leading and directing will follow. This step represents an important management activity because it is concerned with the dynamic interaction between the nurse, the male partner and the female partner. As indicated in the situational analysis the dynamic that prevailed mostly between the nurses, male partners and female partners includes poor interpersonal relationships, negative perceptions of male involvement in $\mathrm{RH}$, inferior communication, negative attitudes, a lack of trust and respect, and fear of the unknown as result of the social and cultural factors. Muller et al. (2006) suggest that, in order to manage this dynamic so as to attain the goal and the outcome of male partner involvement in $\mathrm{RH}$, the registered nurse, as agent, may facilitate this process by means of leadership principles and strategies. As indicated in chapter 4, the leadership strategies of conflict management, decision making, problem solving, time management and the management of change, may be employed. The strategies pertaining to each principle of leadership needed in the facilitation process of male partner involvement in RH are discussed in detail in chapter 6 .

\subsubsection{Phase 4: maintaining a conducive environment}

After the management process phases, the phase of maintaining a conducive environment commences. The aim of this phase is to strengthen and to maintain the interpersonal relationships within the environment that provides RH services. A conducive environment is characterised safety, interest, commitment, motivation, patience, support, respect, adequate resources and networking.

Safety refers to the state of being protected from any danger or harm (Hornby, 2000). Health facilities encompass several physical and psychological factors that may influence or affect the decisions of life partners either to become involved or not to become involved in the RH services (Perry, 1997). Safety, in this study, is expressed in terms of the privacy and confidentiality of both information and treatment. It is essential that the registered nurse identify those factors that threaten the safety of the partners in the RH facilities. In this study a lack of privacy and a lack of confidentiality are among the main factors that negatively affect male partner involvement in RH. The vision, mission and value of the health facilities that provide $\mathrm{RH}$ should clearly indicate the way in which safety will be guaranteed in terms of privacy and confidentiality.

The word "interesting" means attracting attention as a result of a special, exciting or unusual quality (Hornby, 2000). The environment in which RH services are delivered should attract the attention of the partners in terms of the availability of adequate resources, safety, privacy and recognition of the partners' presence at the health facilities. Networking, mutual cooperation, collaboration, communication, the sharing of responsibilities, joint decision-making, trust, respect and confidentiality will make it possible both to promote and to maintain the highest professional standards and this will, in turn, help ensure confidentiality in respect of the information given to clients about their diseases of problems regarding $\mathrm{RH}$.

Commitment refers to a promise to support or to do something (Hornby, 2000). In this study the RH facilities and institutions should be committed to providing quality services in order to facilitate male partner involvement in RH. It is expected of the agent ensure that the human, material, and physical resources, as well as time and information, are managed properly.

Motivation is the term used to describe both the extrinsic conditions that stimulate certain behaviour and the intrinsic responses that make human beings what they are. The intrinsic is described in terms of needs, wants and drive (Oxford Dictionary, 2000). In this fourth phase, motivation is expressed in terms of recognition, praise and reward For example, the needs and deficiencies of the partners are identified and action taken to meet these needs and resolve the deficiencies.. In terms of the affiliation motive the male partner should feel that his involvement in $\mathrm{RH}$ will be regarded with approval by most members of the community. As regards the security motive, the male partner should experience no doubt that he and his partner's problem(s) will remain confidential and that their needs will be cared for in an holistic manner.

Hornby (2000) describes support as the act of helping or encouraging by saying or showing agreement while respect may be defined as a feeling of admiration which arises in response to positive qualities. In the RH environment the agent should be able to spend time with the partners and be visibly involved in listening, 
interpreting their body language, showing sympathy and responding to their problems. In his/her communication with the partners the registered nurse must establish a trust relationship by being honest, open and respectful in terms of both their problem and their presence. Any information which is in the interests of the partners should not be withheld, but it is essential that personal secrets and confidential information is not divulged (Barker, 1990). In order to build such a relationship (interpersonal relationship) the registered nurse must treat the partners with respect, courtesy, care, and concern (Barker, 1990). The registered nurse must also be consistent in her behaviour and keep any promises made If a leader is to be trusted that leader needs to be mature wise, autonomous, competent, goal directed, empathetic and with a solid sense of ethics (Booyens, 1998).

Hornby (2000) and Muller et al. (2006) define adequate resources as assets that may be used to help achieve the aims of the organisation. These resources may be human, physical or material. In this study adequate resources, whether human, material or physi$\mathrm{cal}$, are maintained through planning, organising, leading and control. Networking is a process that includes the establishing and use of contacts for information, advice and support. The aim of networking is to gather and provide information across work groups; encourage the exchange and sharing of ideas, to offer support, and to foster and share expertise and services (Barker \& Gaut, 1996).

\subsubsection{Phase 5: control and terminus/outcomes}

After the phases of planning, organising, and leading it becomes incumbent for the registered nurses to implement control as the fourth step in the management process in order to ascertain whether all the activities suggested in the previous three steps have been implemented in accordance with the strategic intent and subsequent strategies and plans. Accordingly, the aim of controlling is to ensure that the goals and the outcome as suggested are accomplished. Muller et al. (2006) suggest the following four steps in terms of control in order to guide the registered nurse during the process: setting the standard, measuring actual performance, evaluating deviations, rectifying deviations and feedback.

Setting the standard may be defined as a written description or statement of the expected level of performance with reference to the structure process and the outcome. In this respect standards may be situational analysis standards, developing partnership standards, management standards and control and outcome standards. The standard(s) should be relevant, realistic, attainable and measurable. Thus, these standards function as a foundation in respect of the goals that were formulated during the planning phase.

Measuring actual performance, during the facilitation process from phase 1 to phase 3 - information was collected, collated and presented in order to identify any disparities between performance standard and actual performances based on the activities identified during each phase. The aim of this step is to enable the registered nurse to identify any deviations and problems. However, it is expected that the registered nurse should collect valid, quantifiable and absolutely reliable data. Each standard indicated in 'setting standards' will determine the type of information that must be collected and also the way in which this information should be collected.

Evaluating deviations: This step comprises the determination of the performance gap between the performance standard and the actual performance. The registered nurse, as agent in the facilitation of male partner involvement in $\mathrm{RH}$, should ensure that the deviation/disparity is trustworthy (reflects the truth). In addition, non-compliance should be determined and evaluated with reference to its impact; contributory factors should be investigated in order to guide the nature and the scope of any corrective/remedial action which may be required; the extent of the deviations should be determined and a decision taken as to whether these deviations justify further investigation.
Rectifying deviations: The aim of this step is to determine the need for collective or remedial action and to ensure that deviations do not occur. The rectification of the deviation proceeds in accordance with the problem identified. Consultation and counselling are vital in this regard.

Feedback: Sufficient feedback to the partners from either the registered nurse or the enrolled nurse is one of the most important measures to improve productivity and outcomes. This feedback should be planned in such a way that the registered nurses should be able identify the key areas in terms of which feedback should be given, for example, the registered nurse must decide the details of the topic to be conveyed, and this might include deficiencies, successes, problems, or acknowledgement. The receiver (partners) should be able to understand situation fully and also what he/she is expected to do after the feedback. However, in order to accomplish this it is essential that there be mutual respect between the stakeholders.

The person providing the feedback should be specific, timely, descriptive, non-judgmental, diligent, constructive, positive and aware of emotional status of the client. The person(s) receiving the feedback must clarify the type of feedback which he/she is seeking in order to benefit from this feedback. The atmosphere should allow for open-mindedness, friendliness, respect, trust and justice. Attentive listening skills are also essential if the feedback is to be successful.

\subsection{Evaluation of the model}

This study was conducted under the supervision of five independent experts, namely, two experts in model development and qualitative research, two experts in qualitative research and education, and one expert in education, management, model development and qualitative research. During the year of study consultations were held with the researcher, two supervisors and two experts (professors) in research and model development in order to clarify the model. Various stakeholders, such as experts in model development, peer group members and staff members from the nursing profession were also given the opportunity to provide their inputs into the model. The model was also evaluated in accordance with the criteria for theory generation of Chinn and Kramer (1991) in terms of which the following questions are posed:

\subsubsection{How clear is the model?}

The concepts and statements used in model development were explored and described using the protocols and steps described by Wilson (1989) in Walker and Avant (1998). An intensive literature review was conducted in order to identify the attributes and connotations of a partnership and the facilitation of male involvement in RH. The major related concepts which had been identified were defined and described so as to enhance the clarity of the model.

Throughout the study both the major concepts and the related concepts were used in a consistent fashion. The conceptual map derived from the conceptual analysis provided a framework within which to collect the empirical data in the form of focused groups which comprised the male and female partners as well as the nurses.

The identification of the concepts and statements used in this model for facilitating male involvement in $\mathrm{RH}$ were carried out in a systematic way, for example, the researcher commenced with an exploration and description of the empirical data using different research methods and techniques, This was followed by the concept analysis and conceptualisation using the various methods described by Walker and Avant (1988) - the researcher used the methods of synthesis, derivation and analysis strategies for the formulation of concepts and statements and for the model development. The researcher also used qualitative synthesis (data synthesis from empirical data) and literal synthesis (data synthesis from literature).

The following procedures for concept derivation were used - the researcher identified the concepts and familiarised himself with 
existing literature relating to the topic of interest. This involved not only reading the literature but also critiquing the level and usefulness of the existing concepts to be found in the literature. The researcher read widely in order to identify relatedness and dissimilarities to the concepts identified and then chose parent concepts or set of concepts from other fields to use in the derivation process. Finally, the researcher redefined the concepts or sets of concepts from the parent field in terms of the topics of interest.

\subsubsection{How simple is the model?}

The concepts used in a model include simple and specific concepts which are supported by the diagram (sketch) in all the phases while core concepts only are used. There is evidence of simplicity, for example, the model is easy to understand and to implement because it indicates, firstly, the context in which RH delivery should be taking place (health context, male and female partner context), secondly, the agent or the facilitators of the process, and, thirdly, the recipients (male and female partners) and the procedures to follow in order to involve male partners in $\mathrm{RH}$.

\subsubsection{How accessible is the model?}

There is evidence of empirical accessibility in the model due to the fact that the definitions generated for the model are specific and also because related concepts have been defined, therefore, there is conceptual meaning.

\subsubsection{How important is the model?}

The importance of this model lies in the fact that the model may be used in nursing practice, nursing education and research. In terms of nursing practice this model, which aims at facilitating male involvement in the RH context, could be suitable for all the stakeholders at all levels, namely, community, district, national and regional level. In terms of nursing education, the strategies and approaches in the model may be utilised in the training and educating of the male and female partners and in the community at large on ways in which to participate in $\mathrm{RH}$ and also on ways in which to involve, promote participation in, and motivate male partners to become involved in RH. The model was carried out in five phases, namely, situational analysis, development of the partnership, management process, conducive environment and control and outcome. A model also indicated on the significant factors that the facilitator needs to consider, for example, the mobilisation of resources as well as the management of these resources, empowerment of the stakeholders as well as partnerships and the development of networking. The model may also provide essential tools in training the nurses during their initial basic training. In terms of management the model clearly outlines the process of management, for example, planning, organising, leading and control within the RH context. These management approaches within the RH context may be applied not only within a health environment, but within any organisation which wishes to involve the male partner. In terms of research the model may be used as paradigm for those who wish to conduct further studies on males and RH.

\section{Conclusion}

This paper dealt with the framework of a model to facilitate male partner involvement in RH. An overview of the model was provided as well as a description of the purpose and the structure of the model. The structure of the partnership model was described using the assumptions on which the model is based and the concept definitions. Related statements are inherent in both the assumptions and definitions the nature of the structure and the process of the model.

This process of facilitation of male partner involvement in the $\mathrm{RH}$ is carried out in five phases, namely, phase 1 which deals with the situational analysis, phase 2 which is concerned with the devel- opment of a partnership between the agent and the recipients through shared vision, networking, mutual cooperation, collaboration, communication, sharing of responsibility, joint decisionmaking and motivation. Phase 3 involves the management process which comprises planning, organising directing and controlling, while phase 4 deals with the promoting of a conducive environment through safety, interest, commitment, motivation (recognition, praise and reward), support, adequate resources and networking. Phase 5 involves control and outcome in terms of which the registered nurse sets the standard of monitoring, measuring performances, rectifying deviations and providing feedback to the stakeholders. The outcome of the entire programme is male partner involvement in RH. The model was evaluated in accordance with the following set of criteria prescribed by Chinn and Kramer (1991, p. 129): clarity, simplicity, generality, accessibility and importance of the model.

\section{References}

[1] Rossouw, D. (2000/01). Concepts, meaning and definition, in Intellectual tools: skills for the human science, edited by D. Rossouw. Pretoria: Amabhuku. 7-13.

[2] Chinn, P.L., \& Kramer, M.K. (1991). Theory and nursing: a system approach. Second edition. ST. Louis: company.

[3] UNESCO. (2002). Universal Declaration on cultural Diversity [Online]. Retrieved November 20, 2007, from http://www.unesco.org/education/imld2002/universal-decla.shtml. Issued on International

[4] UNFP (b), (2003), retrieved October 29, 2003 from http://www. nnfpa.org/profile/overview- euroasia. Http

[5] Nell, M., Landry, L., Wilknson, D, Tzanis J. 1998. Mens as partner in Reproductive health: From Issues to Action.

[6] Bureau of Reproductive Health Care. (2002). Washington D.C.

[7] Jackson, H. (2002). AIDS in Africa. Continent in Crisis. Zimbabwe: SAFAIDS.

[8] Samba, E.M. (1999). Health information package of the WHO African Region. Reproductive Health Afr/ inf/ 99:1.

[9] Mbizvo, M.T., \& Bassett, M.T. (1996). Reproductive health and AIDS prevention in Sub-Saharan Africa: The case for increased male participation. Health Policy and Planning 11(1): 84-92. http://dx.doi.org/10.1093/heapol/11.1.84.

[10] United Nations (UN). (1995). Report of the fourth World Conference on Women, Beijing, China. UN: New York.

[11] United Nations Population Fund (UNFPA). (1999). Meeting the goals of the ICPD Consequences of resources shortfalls up to the year 2000. UN: New York.

[12] United Nations Population Funds (UNFPA). (2001). ICPD program for action. New York: UNFPA.

[13] Ahlert, D., Becker, J., Hoeren, T., \& Klein, S., (2004). Marketing innovation service solution with inter - organizational service network: Opportunities and threats. Marketing innovation service solutions. (26), 2004: 5- 46.

[14] Republic Of Namibia. (2004). Nursing Act 8 of 2004. Government Gazette of the Republic of Namibia. Windhoek: Namibia.

[15] EL Ansari, W., Phillips, C.J. \& Zwi, A.B. (2004). Public Health Nurse Perspective on collaborative Partnership in South Africa. Public Health Nursing. Vol.21. No.3. 2004. $32-41$. http://dx.doi.org/10.1111/j.0737-1209.2004.021310.x.

[16] Blomqvist, K., Hurmellina, P. \& Seppanen, R. (2005). Playing the collaboration game right - balanceing trust and contracting. Tech-

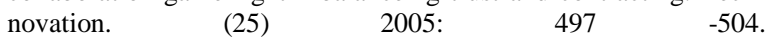
http://dx.doi.org/10.1016/j.technovation.2004.09.001.

[17] Senge, P. 2001. The Enzine for Facilitators [online]. The Fifth discipline Field book. Master Facilitator Journal. Retrieved December, 10, 2007 from http://www.masterfacilitator.com/daialogue.html

[18] EL Ansari, W., Phillips, C.J. \& Zwi, A.B. (2004). Public Health Nurse Perspective on collaborative Partnership in South Africa. Public Health Nursing. Vol.21. No.3. 2004. 32 - 41 . http://dx.doi.org/10.1111/j.0737-1209.2004.021310.x.

[19] Carnewell, R. \& Carson, A. (2004). Understanding partnership and collaboration working in partnership: from theory and practice.

[20] Sirmon, J, Rana, N., Kostishack, P. (2002). Report to the USDA Forest Services on phase II of the partnership development program "Learning While Doing": A model For Working in Collaboration and Through Partnership. Pinchot Institute for Conservation: Washington, D.C. 
[21] Blomqvist, K., Hurmellina, P., \& Seppanen, R. (2005). Playing the collaboration game right - balanceing trust and contracting. Tech$\begin{array}{llll}\text { novation } & (25) & 2005: & 497\end{array}$ http://dx.doi.org/10.1016/j.technovation.2004.09.001.

[22] Barker, A. M. (1990). Transformational Nursing leadership. London. Williams and Wilkins.

[23] Christies, C.N. (2000) Employing a cognitive theory of collaboration to guide team process and tool selection. Vienna: evidence Based Research Inc. 2000: 1 -11.

[24] Bohm,D. (1996). On the dialogue. London: Routledge. http://dx.doi.org/10.4324/9780203180372.

[25] Daniels, T.D.; Spiker, B.K. \& Papa, M.J. (1997). Perspective on organizational communication.4th Edition. Boston, MA: McGraw Hill.

[26] Clark, H.F. \& Maas, H. (1998). Comox Valley Nursing centre: from Collaboration to empowerment. Public Health nursing.Vol.15, No.3 1998: 216 - 224.

[27] Oxford dictionary. (2002). Online. Retrieved 2002 Http://www.oxforddictionaries.com/defenition/enlish/recepient?q=r ecipients.

[28] Muller, M. (2006). Nursing Dynamics. $1^{\text {st }}$ Edition. Johannesburg: Heinemann.

[29] Voght, J. F. \& Murrell, K.L. (1990). Empowerment in Organization: How to spark exceptional performance. Amsterdam: Pfeiffer.

[30] Douglas, C., Martin, J.S., \& Krapels, R.H. (Eds). (2003). the experience and views of self-management of people with schizophrenia, in Proceedings of the Association for Business Communication Annual Convention on Change Communication, Florida State University: $1-10$.

[31] Horny, M. (2000). Concise Dictionary of Linguistics. Oxford University press.

[32] Muller, M, Bezuidenhout, M., \& Jooste, k. (2006). Health care service management. Cape town: Juta

[33] Gerber, P. D., Nel P.S. (1987).Human Resources Management. Johannesburg: Southern.

[34] Chinn, P.L., \& Kramer, M.K. (1995). Theory and nursing: a system approach. Third edition. ST. Louis: Mosby Company.

[35] Levenstein, A. (1984). Feedback improves performance. Nursing Management, 15(2), 64-66. http://dx.doi.org/10.1097/00006247198402000-00017.

[36] Charlton, G. (2000) Human habits of highly effective organizations. The human race. Cape Town.

[37] Barker, A. M. (1990). Transformational Nursing leadership. London. Williams and Wilkins.

[38] Barker, L. L., \& Gaut D.A. (1996). Communication. $7^{\text {th }}$ edition. Allyn \&Bacon: USA.

[39] Senge, P. 2001. The Enzine for Facilitators [online]. The Fifth discipline Field book. Master Facilitator Journal. Retrieved December, 10, 2007 from http://www.masterfacilitator.com/daialogue.html

[40] Botes, A. (2000/01). Validity, reliability and trustworthiness, in Intellectual tools: Skills for the human science, edited by D Rossouw Pretoria Amabhuku.

[41] Booyens, S.W. (1998). Dimension of nursing Management. Second edition. Cape Town: Juta \& Co, Ltd.

[42] Charlton, G. (2000) Human habits of highly effective organizations. The human race. Cape Town.

[43] Chinn, P.L., \& Kramer, M.K. (1991). Theory and nursing: a system approach. Second edition. ST. Louis: company.

[44] Walker, L.D., \& Avant, K.C. (1998). Strategies for theory construction in Nursing. Norwalk: Appleton and Lange.

[45] Walker, L.O., \& Avant, K.C., (2004). Strategies for theory construction in nursing. Fourth edition. California: Pearson Prentice Hall. 